\section{Iron meteorites}

Handbook of Iron Meteorites: Their History, Distribution, Composition and Structure. By V. F. Buchwald. Vols 1-3 +Suppl. Vol. 1: pp.xiii +1-244+8; vol. 2 pp. $245-820+8$; vol. 3 : pp.821-1,418 +8 . (University of California: Berkeley, Los Angeles and London, 1976.) $£ 98$.

ThIS HANDBOOK weighs $6.39 \mathrm{~kg}$, or somewhat less than "the most common size of an iron meteorite" (p27). It is a unique monograph in three volumes, and a fitting tribute to the author as scientist-explorer and to his patience and determination in tracking down meteonites from the deserts of Greenland to the museums of Mexico.

Volume 1 is a general introduction under various headings such as "The minor bodies of the solar system" and "Statistical and historical notes". "Classification" includes stones and stony-inons in addition to irons; that for the C3-C4 carbonaceous chondrites was never really accepted and was superseded by 1972 , when the book was largely completed; the author lists Shergotity as an "anomalous achondrite", but omits Padvarninkai and Zagami (Nature 213, 1, 111; 1967). The modern structural and chemical classification of inon meteorites is lucidly outlined and well illustrated using figures and tables, and the mineralogy of irons and their primary (cooling) and secondary (for example, shockproduced) structures are comprehensively described.

The text of the first volume ends with "Meteorite anges", which is too brief a summary and sometimes misleading. It is stated, for example, that the "majority" of meteorites dated by the $\mathrm{Rb}-\mathrm{Sr}$ method lie on the same 4.55 Gyr isochron "and thus are cogenetic". I think that few scientists, if any, would agree that Estherville, Nakhla, Orgueil, Weekeroo Station and Forest City (also Apollo 12013!) are cogenetic (Fig. 229A). After the text are various appendices summarising data on different aspects of meteorites, together with a wide list of references not quite comprehensive to the end of 1972. In this introductory volume, I would like to have seen a glossary of terms for the benefit of the wide range of scientists to whom this book should be of interest-for example, what is a Hugoniot curve? (p135).

Volumes 2 and 3 are the fonte of the work. In these are given, in alphabetical order, detailed and excellently illustrated accounts of the iron metenriites. Such information is not available elsewhere. When possible, a history of the meteorite is presented thoughtfully and sensitively-for interesting reading see, for example, "Ainsworth" and its probable relatives, and "Elbogen". Then comes the location of material, followed by the chemical and structural 'fingerprint' of the inon, if known. The author, with J. T. Wasson and coworkers, by establishing the identity of various irons has rendered a great service to meteoriticists, and this is apparent from the book. Not all diagnoses, however, are apparently proving to be correct; "Verkhne Dnieprovsk" not only covers mis-labelled Augustinovka but includes the British Museum (Natural History) specimen which belongs to Group IIE and probably represents a distinct iron (see $\mathbf{J}$. T. Wasson, Meteorites, Springer, Berlin, 1974); new and as yet unpublished measurements of the distribution of $\mathrm{Ni}$ between the phosphide and metal indicate that Buchwald's "North Chile" might include two different meteorites.

\section{Spokes missing in ecological wheel}

Ecological Relationships. By N. Gilbert, A. P. Gutierrez, B. D. Frazer and R. E. Jones. Pp. 156. (Freeman: Reading and San Francisco, December 1976.) $£ 3.50$.

THIS book is very different from other recent ecological texts. It advocates that the key to understanding ecological relationships is to build detailed computer simulations; these should be based on a comprehensive knowledge of the behaviour, physiology and population characteristics of the component organisms, studied in the field, where the effects of climate and season play an overwhelming role. Simple models, laboratory experiments and general abstractions are to be avoided. It is a point of view which obviously deserves to be aired, but it is not this, but rather its faults, which sets the book apart.

It is full of minor irritations. The title is misleading; it is not about ecological relationships in general, but mainly about the authors' own work on aphids, ladybirds and cabbage-white butterflies. A large number of key references are in that murky area from "unpublished" to "in press", and since many of the methods and results are presented in a most cursory manner, their inaccessibility is frustrating. On the other hand, to occupy approximately $10 \%$ of the text with routine Fortran smacks of self-indulgence, particularly when one of the few really interesting results in the book (p30), dealing with the maximisation of fitness in aphids, is presented without any
But this must not detract from the real value of the work as a source of data, for although interpretation may change (as the author admits), the data should not, except for additions.

This book is a necessity for reference use by all concerned with meteorites, and in addition should be of interest to metallurgists, geochemists and other earth scientists. And apart from that, it makes pleasant browsing, reading the varied histories of these unusual and often revered objects. Although the price is high, there are 21.25 illustrations per $£$, there being 2,124 figures; the price therefore seems reasonable. Any European wishing to save should try to have the book bought in the USA and mailed to Europe.

Robert Hutchison

Robert Hutchison is a Principal Scientific Officer in the British Museum (Natural History), where he is responsible for the national collection of meteorites.

of the "fairly involved algebra" used to derive it.

I have other, more serious criticisms. The authors dismiss "simplistic theories" without apparently taking the trouble to understand them. Thus, having rejected the concepts of population equilibria and stability, they nevertheless find it necessary to talk about "stability" on p75, but put it in quotation marks and qualify it by saying "however defined", thus ensuring that it is meaningless. They attack predator-prey models but rediscover most of the things that current theory already incorporates, such as the voracity and activity of the predators ( $p 80)$, their response to patchily distributed prey ( $\mathrm{p} 49)$, the importance of limited searching time (p39 and p135) and time wasted in non-hunting activity (p41). And on p81, they rediscover the properties of $r$ and $K$ species, cursorily dismissed earlier in the book, instead labelling them "ephemeral" and "sessile". I could give many more examples.

Who is this book aimed at? Certainly, it isn't suitable for undergraduates, because although it advocates a methodology, its treatment and use of the literature is too superficial to teach them much. It might be useful to research workers, but it is more likely to put them off than convert them. There is obviously an urgent need to test ecological ideas in the field, but in saying so, this book seems merely to have rediscovered the wheel: unfortunately it has a lot of spokes missing and its square.

John Lawton

John Lawton is Lecturer in Ecology at the University of York, UK. 